OPEN ACCESS

Fabrication of Copper/Multiwalled Carbon Nanotube Composites Containing Different Sized Nanotubes by Electroless Deposition

To cite this article: Susumu Arai and Takuma Osaki 2015 J. Electrochem. Soc. 162 D68

View the article online for updates and enhancements. 


\title{
Fabrication of Copper/Multiwalled Carbon Nanotube Composites Containing Different Sized Nanotubes by Electroless Deposition
}

\author{
Susumu Arai*,z and Takuma Osaki \\ Department of Chemistry and Material Engineering, Faculty of Engineering, Shinshu University Nagano-shi, \\ Nagano 380-8553, Japan
}

\begin{abstract}
$\mathrm{Cu} /$ multiwalled carbon nanotube (MWCNT) composites containing two different sized MWCNTs were fabricated using an electroless deposition technique in aqueous solution. In order to disperse the MWCNTs in the solution, an anionic dispersant of sodium dodecyl sulfate (SDS) and a polymeric dispersant of hydroxypropyl cellulose (HPC) were used. The dispersibility of the MWCNTs in solution was evaluated by measuring the particle size distribution. The zeta potential for the MWCNTs was also evaluated to examine the dispersibility. Uniform Cu/MWCNT composites containing the two different sized MWCNTs were fabricated through the electroless copper deposition process from a solution containing copper ions, a complexing agent, a reducing agent, and two dispersants, SDS and HPC, in addition to the two different sized MWCNTs.

(c) The Author(s) 2014. Published by ECS. This is an open access article distributed under the terms of the Creative Commons Attribution 4.0 License (CC BY, http://creativecommons.org/licenses/by/4.0/), which permits unrestricted reuse of the work in any medium, provided the original work is properly cited. [DOI: 10.1149/2.0971501jes] All rights reserved.
\end{abstract}

Manuscript submitted October 20, 2014; revised manuscript received November 13, 2014. Published December 1, 2014.

Carbon nanotubes (CNTs) have excellent thermal conductivity, ${ }^{1}$ stable electrical resistance in the presence of high currents ${ }^{2}$ as well as superior mechanical properties. ${ }^{3,4}$ Metal/CNT composites are therefore expected to be potential functional materials and there have been many investigations concerning fabrication of metal/CNT composites. ${ }^{5}$ In particular, $\mathrm{Cu} / \mathrm{CNT}$ composites have attracted attention due to their applications in electronics and other fields. $\mathrm{Cu} / \mathrm{CNT}$ composites thus far have mainly been fabricated using metallurgical methods such as spark plasma sintering, ${ }^{6-10}$ hot press sintering, ${ }^{11-14}$ high pressure torsion, ${ }^{15,16}$ microwave sintering, ${ }^{17}$ and the rolling method. ${ }^{18}$ However, the dispersibility of CNTs in the copper matrix has often been a problem.

Electrodeposition, an electrochemical method, has been investigated for fabricating $\mathrm{Cu} / \mathrm{CNT}$ composites. ${ }^{19-21}$ This method has several advantages. For instance, $\mathrm{Cu} / \mathrm{CNT}$ composites can be formed at ambient temperature and atmospheric pressure. Different from the electrochemical method, a chemical method called electroless deposition enables the formation of metal layers on both conductive and nonconductive objects. Our group has previously reported the frictional properties of $\mathrm{Cu} /$ multiwalled carbon nanotube (MWCNT) composites fabricated using the electroless deposition method. ${ }^{22}$ With regard to the thermal properties of metal/CNT composites, Al/CNT composites containing different sized CNTs fabricated using a metallurgical method showed excellent high thermal conductivity. ${ }^{23}$ Therefore, $\mathrm{Cu} / \mathrm{CNT}$ composites containing different sized CNTs are expected to be potential candidates for materials with high thermal conductivity and other functional materials.

To realize the formation of uniform $\mathrm{Cu} / \mathrm{MWCNT}$ composites containing different sized MWCNTs by electroless deposition, the dispersion of the MWCNTs in solution is important. Since MWCNTs are hydrophobic, the introduction of hydrophilic groups, such as the hydroxyl group or carboxyl group, on the surface of the MWCNTs and/or the addition of dispersants of MWCNTs are needed to disperse the CNTs in aqueous solutions. To graft hydrophilic groups on the surface of CNTs, acid treatment, ${ }^{24}$ heat-treatment, ${ }^{25}$ and plasma treatment ${ }^{26}$ have been explored. These methods basically destroy the sp2 carbon bonding of CNTs. The anionic dispersing agent sodium dodecyl sulfate (SDS) has been investigated extensively as a surfactant for CNTs, ${ }^{27-40}$ and other dispersing agents such as a salmon DNA, ${ }^{41}$ a polysaccharide chitosan ${ }^{42}$ and pyrene-capped polystyrene, ${ }^{43}$ have also been investigated. Furthermore, the combination of different kinds of surfactants, such as SDS and hydroxypropyl methyl cellulose, has been attempted. ${ }^{44}$ Generally, the dispersibility of particles in aqueous solutions decreases in the presence of ions.
In the present study, the fabrication of $\mathrm{Cu} / \mathrm{MWCNT}$ composites containing different sized MWCNTs using an electroless deposition technique was explored. The dispersibility of MWCNTs in electroless copper deposition solutions containing large amounts of ions was investigated and the formation of $\mathrm{Cu} / \mathrm{MWCNT}$ composites incorporating different sized MWCNTs homogeneously was demonstrated.

\section{Experimental}

$\mathrm{CuSO}_{4} \cdot 5 \mathrm{H}_{2} \mathrm{O}, \quad \mathrm{H}_{2} \mathrm{SO}_{4}$, glyoxylic acid, ethylenediamine$\mathrm{N}, \mathrm{N}, \mathrm{N}^{\prime}, \mathrm{N}$ '-tetraacetic acid disodium salt (EDTA $\left.2 \mathrm{Na}\right), \mathrm{PdCl}_{2}$, $\mathrm{SnCl}_{2} \cdot 2 \mathrm{H}_{2} \mathrm{O}, \mathrm{HCl}$, Sodium dodecyl sulfate (SDS), and hydroxypropylcellulose (HPC, viscosity: $2.0-2.9 \mathrm{mPa} \cdot \mathrm{s}$ ) were obtained from Wako Pure Chemical Industries, Ltd. Two different sized commercially available MWCNTs were used. Larger MWCNTs (MWCNT-L) were obtained from Showa Denko K. K. (commercial name: VGCF) and smaller MWCNTs (MWCNT-S) were obtained from Bayer MaterialScience (commercial name: Bay tube C70P). The microstructure of the MWCNT-L and MWCNT-S was analyzed using a field emission scanning electron microscope (FE-SEM, SU-8000, Hitachi Co. Ltd.) and a scanning transmission electron microscope (STEM, HD-2300A, Hitachi Co., Ltd.). SEM and STEM experiments were conducted at an acceleration voltage of $5 \mathrm{kV}$ and $200 \mathrm{kV}$, respectively. The MWCNT-L has a stick shape and the MWCNT-S has a curved shape (Figures 1a and 1d). The diameters of MWCNT-L and MWCNT-S are 100-150 nm and 15-20 nm, respectively (Figures 1a, 1b,1d and 1e). Both MWCNTs undoubtedly have multiwalled structures (Figures 1c and 1f). The lengths of the MWCNT-L and MWCNT-S could not be determined with certainty from the SEM and TEM characterizations, but the catalog values are ca. $10 \mu \mathrm{m}$ and 10-15 $\mu \mathrm{m}$, respectively. Pure copper plates (B-60-P05, Yamamoto-Ms Co., Ltd.) were used as substrates. Pure water from a

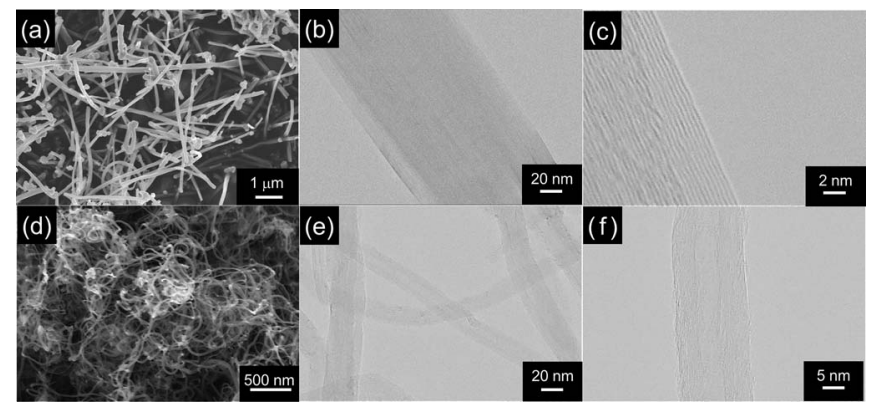

Figure 1. Electron microscopy characterization: (a) SEM image of MWCNTL, (b, c) STEM images of MWCNT-L, (d) SEM image of MWCNT-S, (e, f) STEM images of MWCNT-S. 
water purifier (RFP343RA, Advantec MFS, Inc.) was used in all the experiments.

The base composition of electroless copper deposition solution was $0.06 \mathrm{M} \mathrm{CuSO}_{4} \cdot 5 \mathrm{H}_{2} \mathrm{O}+0.03 \mathrm{M}$ gryoxylic acid monohydrate $\left(\mathrm{CHOCOOH} \cdot \mathrm{H}_{2} \mathrm{O}\right)+0.1 \mathrm{M}$ EDTA $\cdot 2 \mathrm{Na}$. The $\mathrm{pH}$ value was adjusted to 12.1 using $\mathrm{KOH}$. The glyoxylic acid and the EDTA were the reducing agent and complexing agent of $\mathrm{Cu}^{2+}$, respectively. To disperse MWCNTs in the electroless copper deposition solution, dispersants (SDS, HPC and SDS+HPC) were added to the base electroless copper deposition solution, and the MWCNTs were continuously added. To disperse MWCNTs efficiently, the solution with MWCNTs was ultrasonicated for 5 min using a homogenizer (Ultrasonic Homogenizer US-300T, Nissei Co.). The dispersibility of MWCNTs in the electroless copper deposition solutions was evaluated using a laser diffraction particle analyzer (SALD-7000, Shimadzu Co.) at room temperature. The measurements were carried out using the copper deposition solutions without the reducing agent (glyoxylic acid) to avoid the copper deposition reaction during the measurement. The zeta potentials for MWCNTs in solution were evaluated using an electrophoresis zeta potential analyzer (Model 502, Nihon Rufuto, Co. Ltd.). Since the copper electrodeposition solutions are aqueous solutions, the zeta potentials were calculated using the Smoluchowski equation:

$$
u=\frac{\varepsilon_{0} \varepsilon_{r} \zeta}{\eta}
$$

where $\mu$ is electrophoretic mobility, $\varepsilon_{0}$ is relative dielectric constant of water, $\varepsilon_{\mathrm{r}}$ is dielectric constant of vacuum, $\zeta$ is zeta potential, and $\eta$ is the viscosity of the solution. The zeta potential was determined by measuring electrophoretic mobility of MWCNTs. Since the copper deposition solutions have high conductivity and the measurement of the electrophoretic mobility of MWCNTs was difficult, the solutions were diluted approximately 100 times with pure water to reduce the conductivity of the solutions. The measurement was conducted 20 times and the average value was calculated as the measurement value.

In order to start the electroless copper deposition reaction, the copper substrates were pre-treated. The substrates were first degreased
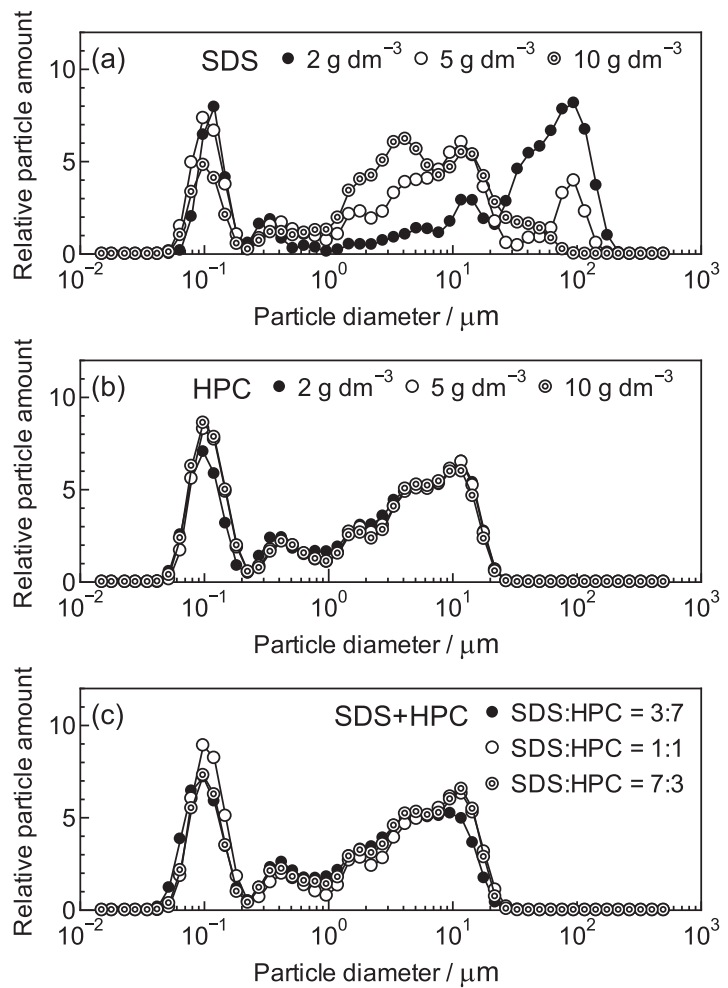

by soaking in a commercially available alkaline solution at $60^{\circ} \mathrm{C}$ for $5 \mathrm{~min}$ (C-4000, C. Uyemura \& Co. Ltd.). After soaking in $10 \% \mathrm{H}_{2} \mathrm{SO}_{4}$, the copper substrates were immersed in a $4.4 \times 10^{-2} \mathrm{M} \mathrm{SnCl}_{2} \cdot 2 \mathrm{H}_{2} \mathrm{O}$ $+0.12 \mathrm{M} \mathrm{HCl}$ solution at $35^{\circ} \mathrm{C}$ for $5 \mathrm{~min}$ to cause adsorption of $\mathrm{Sn}^{2+}$ ions (sensitization). The substrates were then immersed in a $5.6 \times 10^{-4} \mathrm{M} \mathrm{PdCl}_{2}+0.12 \mathrm{M} \mathrm{HCl}$ solution at $35^{\circ} \mathrm{C}$ for $5 \mathrm{~min}$ to form palladium catalytic nuclei on their surfaces (activation). After the pre-treatment, the substrate was immersed in the electroless copper deposition solution with the MWCNTs and dispersants. A $1 \mathrm{~L}$ borosilicate glass beaker was used as the reaction vessel and $500 \mathrm{~mL}$ volume of the solution was used. Copper deposition was carried out at $60^{\circ} \mathrm{C}$ for $120 \mathrm{~min}$ with magnetic stirring.

The fabricated $\mathrm{Cu} / \mathrm{MWCNT}$ composites were observed using the FE-SEM. The mean thickness of the copper deposit was calculated from its weight and the weight of the incorporated MWCNTs was ignored. The phase structure of the $\mathrm{Cu} / \mathrm{MWCNT}$ composites was evaluated by X-ray diffraction (XRD) using $\mathrm{Cu} \mathrm{K}_{\alpha 1}$ radiation with the thin film diffraction mode (SmartLab, Rigaku Co.); the incident angle was $1^{\circ}$.

\section{Results and Discussion}

Figure 2 shows the effects of the dispersants on the dispersibility of MWCNT-L and MWCNT-S in the electroless copper deposition solution. The amount of MWCNTs was $2 \mathrm{~g} \mathrm{dm}^{-3}$ in all the solutions. For the laser diffraction particle size analysis, the particle shape was assumed to be spherical. Since the MWCNTs have a stick or fibrous shape and not a spherical shape, the particle diameters in the figures do not show the diameters of the MWCNTs. However, these charts clearly present the degree of dispersion of the MWCNTs. For the dispersibility of MWCNT-L, the particle size became smaller with increasing SDS concentration (Figure 2a)

In contrast, the particle size distributions for MWCNT-L were almost the same for different concentrations of HPC and they were also shifted toward smaller particle diameters than those with SDS (Fig. 2b). The particle size distributions of MWCNT-L with the
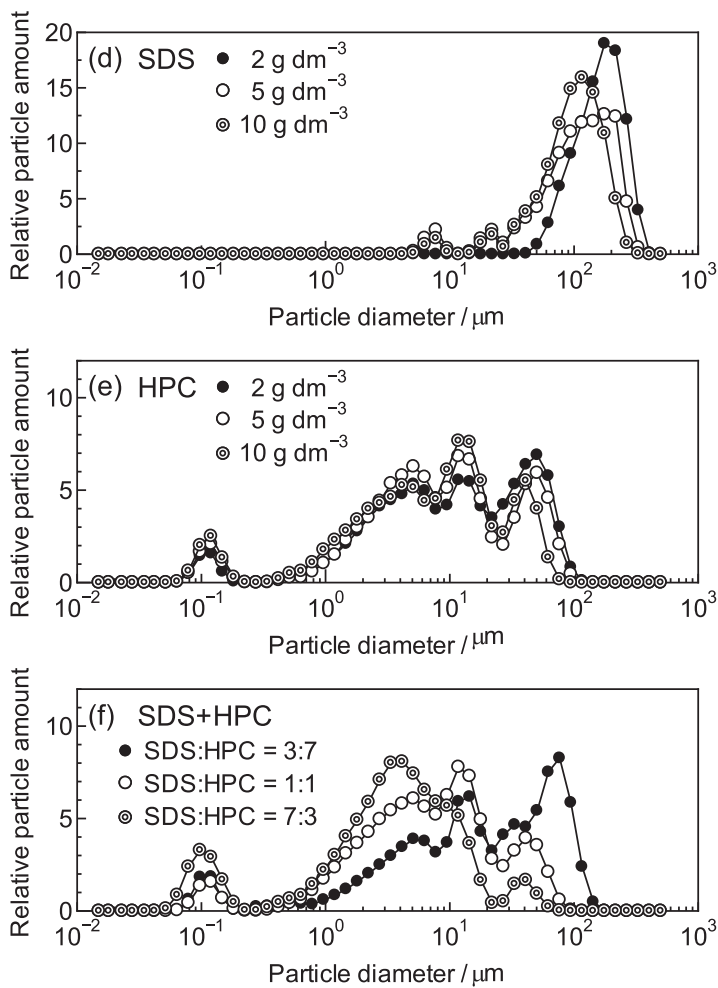

Figure 2. Dispersibility of MWCNTs: Distributions of particle size for (a), (b), (c) MWCNT-L and (d), (e), (f) for MWCNT-S, with SDS, HPC and SDS+HPC, respectively. 

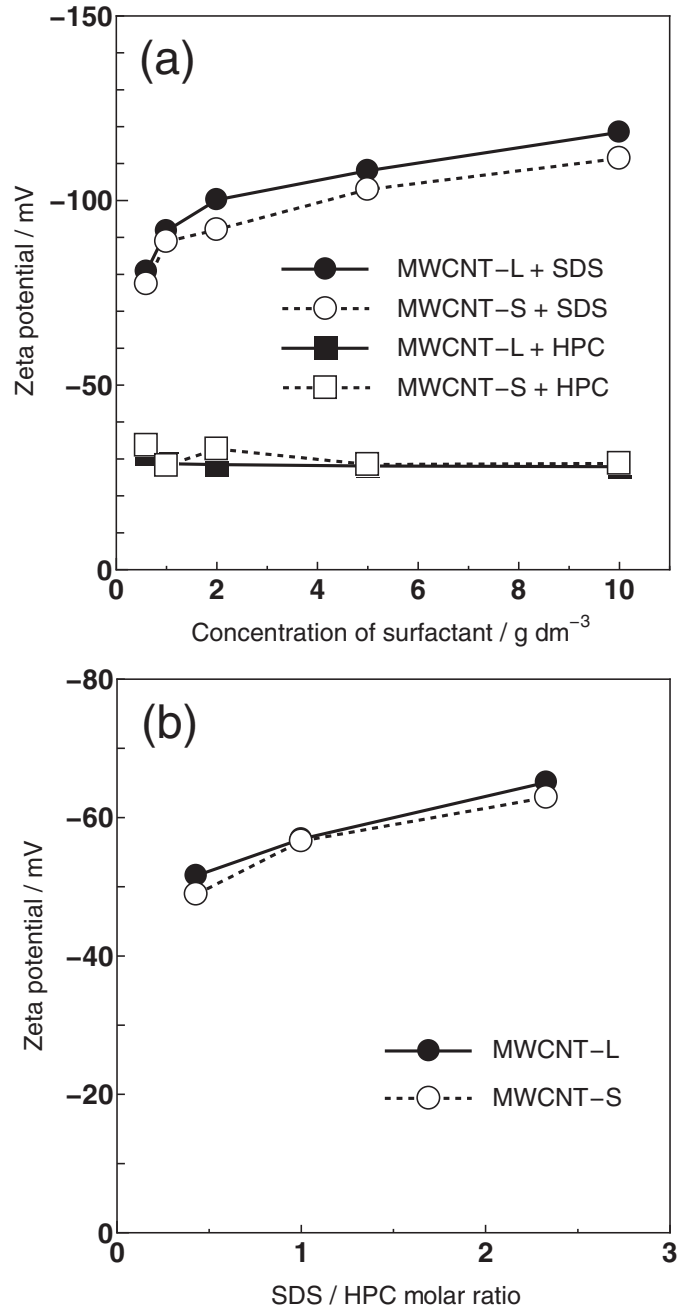

Figure 3. Zeta potentials for MWCNTs: (a) Effects of concentrations of dispersants on zeta potentials for both MWCNTs. (b) Effects of SDS/HPC molar ratio on zeta potentials for both MWCNTs.

combination of SDS and HPC (SDS+HPC) for different SDS/HPC ratios were almost the same as those for HPC (Fig. 2c). This might mean that MWCNT-L is completely dispersed as primary particles with HPC. ${ }^{45}$ For the dispersibility of MWCNT-S, peaks corresponding to larger particle diameter are seen for all SDS concentrations (Fig. 2d). In contrast, the particle size distributions for MWCNT-S are almost the same for different concentrations of HPC and are also shifted toward smaller particle diameters compared to the case of SDS, meaning the dispersibility of MWCNT-S with HPC was clearly higher than that with SDS (Fig. 2e). In the case of SDS+HPC, the dispersibility of
MWCNT-S increased with increasing SDS/HPC ratio. In particular, in the case of SDS:HPC=7:3, the dispersibility of MWCNT-S was higher than that with HPC (Fig. 2f). Thus, the addition of HPC is more effective for dispersing both sized MWCNTs homogeneously in the electroless copper deposition solutions than the addition of SDS, and the combination of SDS and HPC increases the dispersibility of MWCNTs compared to HPC alone.

Figure 3 shows the effects of the dispersants on the zeta potentials for MWCNTs in the electroless copper deposition solutions. All the zeta potentials were negative, and for both MWCNT-L and MWCNT-S, became more negative with increasing SDS concentration. In contrast, the zeta potentials for both MWCNT-L and MWCNT$\mathrm{S}$ were constant at about $-30 \mathrm{mV}$ even when the HPC concentration increased (Fig. 3a). Figure 3b shows the effect of the SDS/HPC ratio on the zeta potential for MWCNTs. The zeta potentials for both MWCNT-L and MWCNT-S shifted toward a more negative direction with increasing SDS/HPC ratio. This was likely due to the increase in the SDS concentration.

In general, the dispersibility of particles in the presence of dispersants is dominated by electrostatic and/or steric repulsion. The electrostatic repulsion effect is related to the zeta potential and is known as the DLVO theory. ${ }^{46}$ The steric repulsion effect is related to the overlap of dispersants adsorbed on each particle. If the change in the Gibbs free energy $(\Delta G)$ of the overlapping reaction is a positive value, the overlap is prevented, resulting in a stable dispersed system. Regarding the dispersibility of MWCNTs with SDS, since the surface of MWCNTs is hydrophobic, the hydrophobic group of dodecyl sulfate anions adsorbs on the surface of the MWCNTs and the hydrophilic group (sulfate group) of the dodecyl sulfate anions is arranged outside of the MWCNTs. Since the sulfate group has a negative charge, the zeta potential for the MWCNTs was shifted toward the negative direction with increasing SDS concentration. Thus the SDS dispersant stabilizes the dispersed system of MWCNTs by electrostatic repulsion. HPC is a polymeric surfactant and similarly adsorbs on the MWCNTs. Since HPC is also a non-ionic surfactant, the zeta potentials for MWCNTs do not change as much, even if HPC adsorbs on the MWCNTs. Therefore, HPC stabilizes the dispersed system of MWCNTs by steric repulsion. In the case of SDS+HPC, both dispersants might be adsorbed on the MWCNTs and thereby stabilize the dispersed system of MWCNTs by both electrostatic and steric repulsion, resulting in the highest dispersibility of both MWCNT-L and MWCNT-S (SDS:HPC=7:3). It has also been reported that SDS forms a complex with HPC which behaves as a dispersing agent toward the suspension by electrostatic and steric repulsion. ${ }^{47}$ The dispersion of MWCNTs with SDS, HPC and SDS + HPC is schematically shown in Figure 4 . The yellow circles show the sulfate groups of the dodecyl sulfate ions.

The fabrication of $\mathrm{Cu} / \mathrm{MWCNT}$ composites was conducted with selected dispersant conditions considering the dispersibility of the MWCNTs. Copper deposition occurs by the following redox reaction: ${ }^{48}$

$$
\mathrm{Cu}^{2+}+2 \mathrm{CHOCOOH}+4 \mathrm{OH}^{-} \rightleftharpoons \mathrm{Cu}^{0}+2 \mathrm{C}_{2} \mathrm{O}_{4}^{2-}+2 \mathrm{H}_{2} \mathrm{O}+\mathrm{H}_{2}
$$

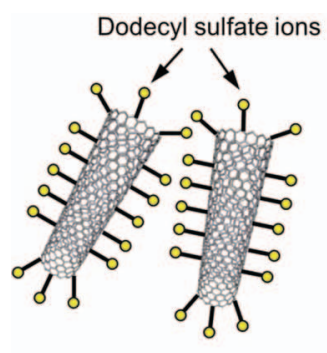

SDS

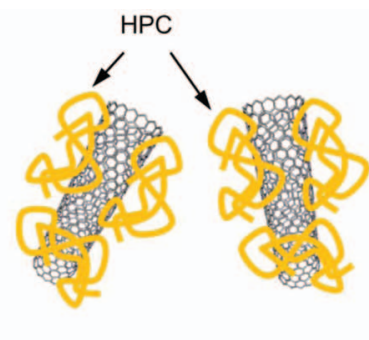

HPC

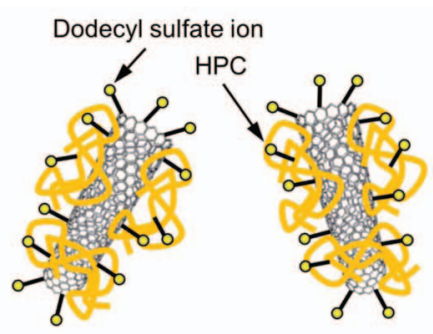

SDS+HPC

Figure 4. Illustrations of dispersion states of MWCNTs with various types of dispersants. Basically MWCNT-L and MWCNT-S should have the same dispersion state. 


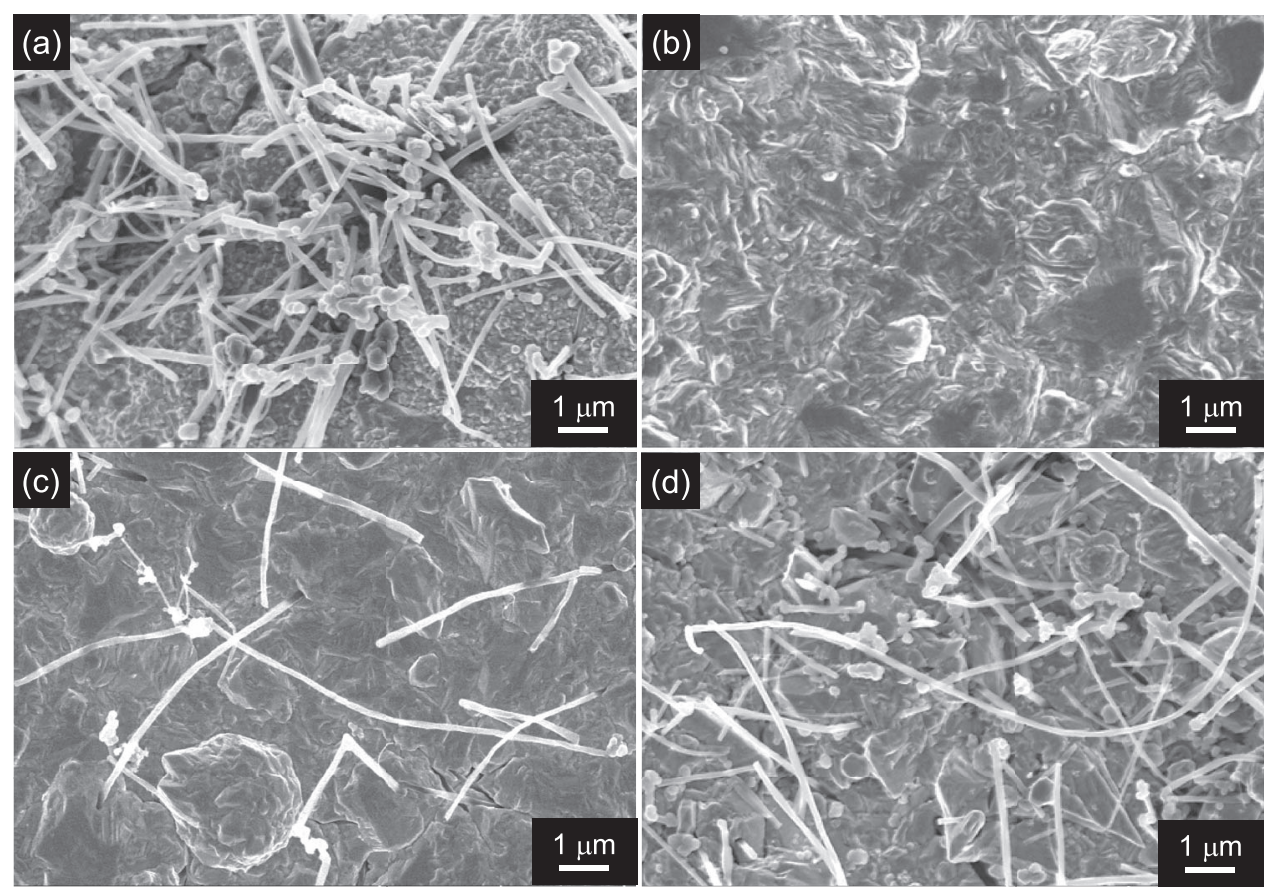

Figure 5. Surface SEM images of deposits fabricated from electroless copper deposition solutions containing MWCNT-L with various types of surfactants: (a) $10 \mathrm{~g} \mathrm{dm}^{-3} \mathrm{SDS}$, (b) $2 \mathrm{~g} \mathrm{dm}^{-3} \mathrm{HPC}$, (c) $1 \mathrm{~g} \mathrm{dm}^{-3} \mathrm{SDS}+1 \mathrm{~g} \mathrm{dm}^{-3} \mathrm{HPC}$, (d) $1.4 \mathrm{~g} \mathrm{dm}^{-3} \mathrm{SDS}+0.6 \mathrm{~g} \mathrm{dm}^{-3} \mathrm{HPC}$.

This overall reaction, which consists of reduction of copper ions and oxidation of glyoxylic acid, proceeds catalytically on the surface of the deposited copper. During this reaction, MWCNTs adsorb on the deposited copper and are incorporated in the copper matrix, resulting in $\mathrm{Cu} / \mathrm{MWCNT}$ composites. The surface morphologies of deposits fabricated from the electroless copper deposition solutions with MWCNTL and MWCNT-S are shown in Figures 5 and 6, respectively. The MWCNT concentration in the electroless copper deposition solutions was $2 \mathrm{~g} \mathrm{dm}^{-3}$ in all cases.
For the case of SDS (Figure 5a), aggregates of MWCNT-L are seen on/in the copper matrix. This corresponds to the dispersibility of MWCNT-L in the solution (Figure 2a). Despite the good dispersibility of MWCNT-L with HPC (Figure 2b), no MWCNT-L was seen on/in the deposited copper (Figure 5b). Since the copper deposition is a catalytic reaction, as described above, the adsorption of a large amount of HPC on the deposited copper surface might suppress the catalytic reaction, resulting in reduced copper deposition and consequently no co-deposition of MWCNTs. Actually, the thickness of the
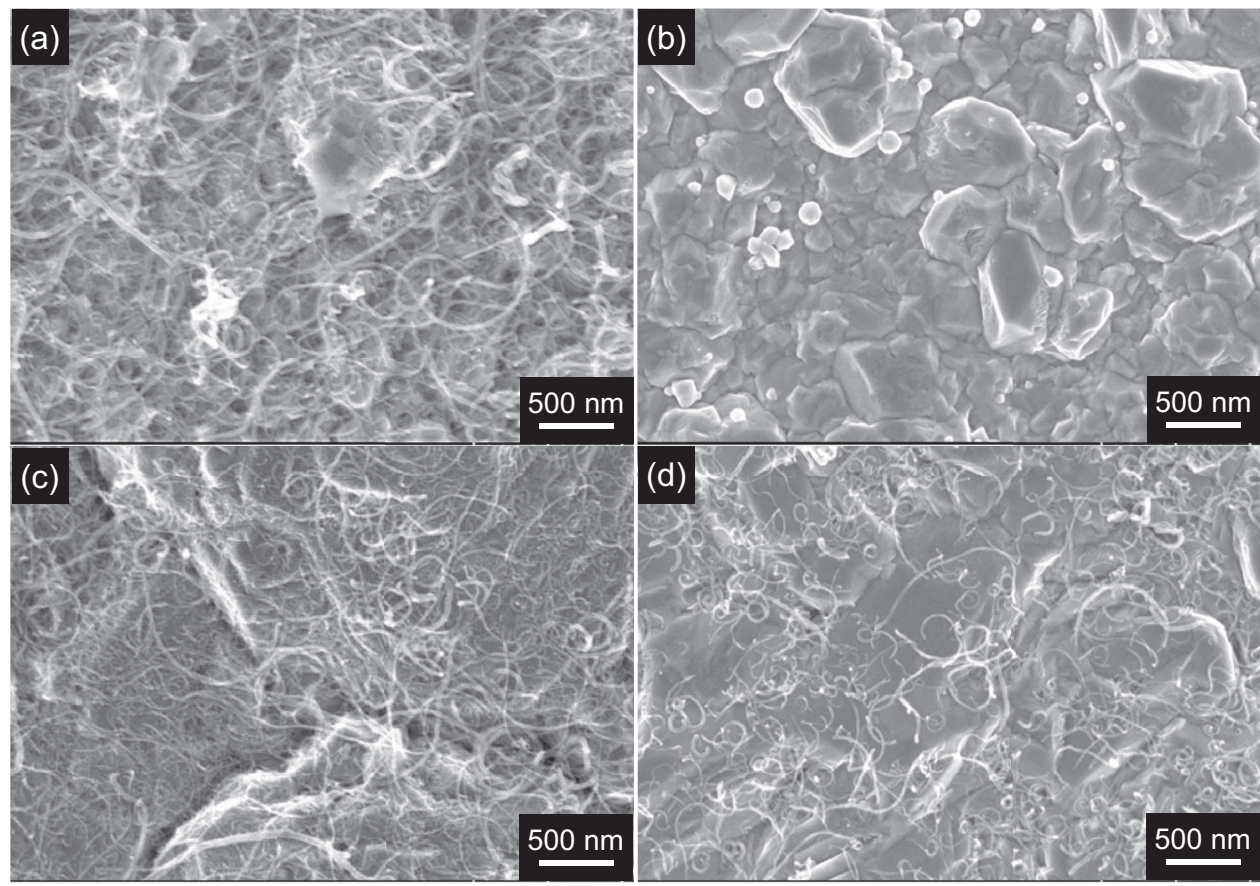

Figure 6. Surface SEM images of deposits fabricated from electroless copper deposition solutions containing MWCNT-S with various types of surfactants: (a) $10 \mathrm{~g} \mathrm{dm}^{-3} \mathrm{SDS}$, (b) $2 \mathrm{~g} \mathrm{dm}^{-3} \mathrm{HPC}$, (c) $1 \mathrm{~g} \mathrm{dm}^{-3} \mathrm{SDS}+1 \mathrm{~g} \mathrm{dm}^{-3} \mathrm{HPC}$, (d) $1.4 \mathrm{~g} \mathrm{dm}^{-3} \mathrm{SDS}+0.6 \mathrm{~g} \mathrm{dm}^{-3} \mathrm{HPC}$. 
Table I. Thickness of copper deposits fabricated under various conditions.

Condition

Thickness $(\mu \mathrm{m})$

MWCNT-L $2 \mathrm{~g} \mathrm{dm}^{-3}+$ SDS $10 \mathrm{~g} \mathrm{dm}^{-3}$

MWCNT-L $2 \mathrm{~g} \mathrm{dm}^{-3}+$ HPC $2 \mathrm{~g} \mathrm{dm}^{-3}$

MWCNT-L $2 \mathrm{~g} \mathrm{dm}^{-3}+$ SDS $1 \mathrm{~g} \mathrm{dm}^{-3}+\mathrm{HPC} 1 \mathrm{~g} \mathrm{dm}^{-3}$

MWCNT-L $2 \mathrm{~g} \mathrm{dm}^{-3}+$ SDS $1.4 \mathrm{~g} \mathrm{dm}^{-3}+$ HPC $0.6 \mathrm{~g} \mathrm{dm}^{-3}$

0.59

MWCNT-S $2 \mathrm{~g} \mathrm{dm}^{-3}+$ SDS $10 \mathrm{~g} \mathrm{dm}^{-3}$

MWCNT-S $2 \mathrm{~g} \mathrm{dm}^{-3}+$ HPC $2 \mathrm{~g} \mathrm{dm}^{-3}$

MWCNT-S $2 \mathrm{~g} \mathrm{dm}^{-3}+$ SDS $1 \mathrm{~g} \mathrm{dm}^{-3}+\mathrm{HPC} 1 \mathrm{~g} \mathrm{dm}^{-3}$

MWCNT-S $2 \mathrm{~g} \mathrm{dm}^{-3}+$ SDS $1.4 \mathrm{~g} \mathrm{dm}^{-3}+$ HPC $0.6 \mathrm{~g} \mathrm{dm}^{-3}$

MWCNT-L $1 \mathrm{~g} \mathrm{dm}^{-3}+$ MWCNT-S $1 \mathrm{~g} \mathrm{dm}^{-3}+$ SDS $10 \mathrm{~g} \mathrm{dm}^{-3}$

MWCNT-L $1 \mathrm{~g} \mathrm{dm}^{-3}+$ MWCNT-S $1 \mathrm{~g} \mathrm{dm}^{-3}+$ HPC $2 \mathrm{~g} \mathrm{dm}^{-3}$

MWCNT-L $1 \mathrm{~g} \mathrm{dm}^{-3}+$ MWCNT-S $1 \mathrm{~g} \mathrm{dm}^{-3}+$ SDS $1 \mathrm{~g} \mathrm{dm}^{-3}+\mathrm{HPC} 1 \mathrm{~g} \mathrm{dm}^{-3}$

MWCNT-L $1 \mathrm{~g} \mathrm{dm}^{-3}+$ MWCNT-S $1 \mathrm{~g} \mathrm{dm}^{-3}+$ SDS $1.4 \mathrm{~g} \mathrm{dm}^{-3}+$ HPC $0.6 \mathrm{~g} \mathrm{dm}^{-3}$

5.7

7.0

0.58

4.5

5.4

0.47

3.2

5.3

*Accurate thickness could not be measured. The deposits were easily peeled from substrates.

copper film was smaller than those of copper films fabricated from solutions with other types of surfactants (Table I). In contrast, uniform $\mathrm{Cu} / \mathrm{MWCNT}-\mathrm{L}$ composites were fabricated from the solutions with SDS+HPC (Figures $5 \mathrm{c}$ and 5d). These results are consistent with the good dispersibility of MWCNT-L in the solutions (Figure 2c). In contrast, dense aggregates of MWCNT-S are seen on/in the copper matrix (Figure 6a). This is consistent with the lower dispersibility of MWCNT-S in the solution (Figure 2d). Similar to the case of MWCNT-L, in spite of good dispersibility of MWCNT-S with HPC (Figure 2e), no MWCNT-S was seen on/in the deposited copper (Figure 6b). The reason for this may be the same as in the case of MWCNT-L with HPC (Table I). In contrast, uniform Cu/MWCNT-S composites were fabricated from solution with SDS +HPC. In particular, the dispersibility of MWCNT-S with SDS:HPC $=7: 3$ is higher than that with SDS:HPC $=1: 1$. These results are also consistent with the dispersibility of MWCNT-S in the solutions (Figure 2f).

Figure 7 shows the surface morphologies of $\mathrm{Cu} / \mathrm{MWCNT}$ composites fabricated using electroless copper deposition solutions containing both MWCNT-L and MWCNT-S with different ratios of SDS and HPC. The concentration of MWCNT-L and MWCNT-S was $1 \mathrm{~g}$ $\mathrm{dm}^{-3}$ and the total amount of surfactants was $2 \mathrm{~g} \mathrm{dm}^{-3}$. In the case of SDS:HPC $=1: 1$, both MWCNTs were incorporated, however, the dispersibility of MWCNT-S was rather low. In contrast, in the case of SDS:HPC $=7: 3$, both MWCNTs were incorporated uniformly. These results are consistent with the dispersibilities of both MWCNTs in the solutions (Figure $2 \mathrm{c}$ and $2 \mathrm{f}$ ) and the appearance of $\mathrm{Cu} / \mathrm{MWCNT}-\mathrm{L}$ (Figures 5c and 5d) and Cu/MWCNT-S (Figures $6 \mathrm{c}$ and $6 \mathrm{~d}$ ).

Figure 8 shows XRD patterns for $\mathrm{Cu} / \mathrm{MWCNT}$ composite films. Figures $8 \mathrm{a}, 8 \mathrm{~b}$ and $8 \mathrm{c}$ show the XRD patterns for Cu/MWCNT-L (Figure 5c), Cu/MWCNT-S (Figure 6c), and Cu/MWCNT-L+MWCNT-S (Figure 7c), respectively. All of the diffraction peaks could be assigned to face-centered-cubic copper. In electroless copper deposition, cuprous oxide $\left(\mathrm{Cu}_{2} \mathrm{O}\right)$ is often formed in the copper deposit, ${ }^{49}$ and it degrades the properties of the copper film. However, no $\mathrm{Cu}_{2} \mathrm{O}$ was formed in the $\mathrm{Cu} / \mathrm{MWCNT}$ composites in the present study. No diffraction peaks due to the MWCNTs can be seen owing to their weak intensity.

Thus, the proposed method is useful for fabricating uniform $\mathrm{Cu}$ /MWCNT composites incorporating different sized MWCNTs homogeneously. Furthermore, this method can be applied not only to

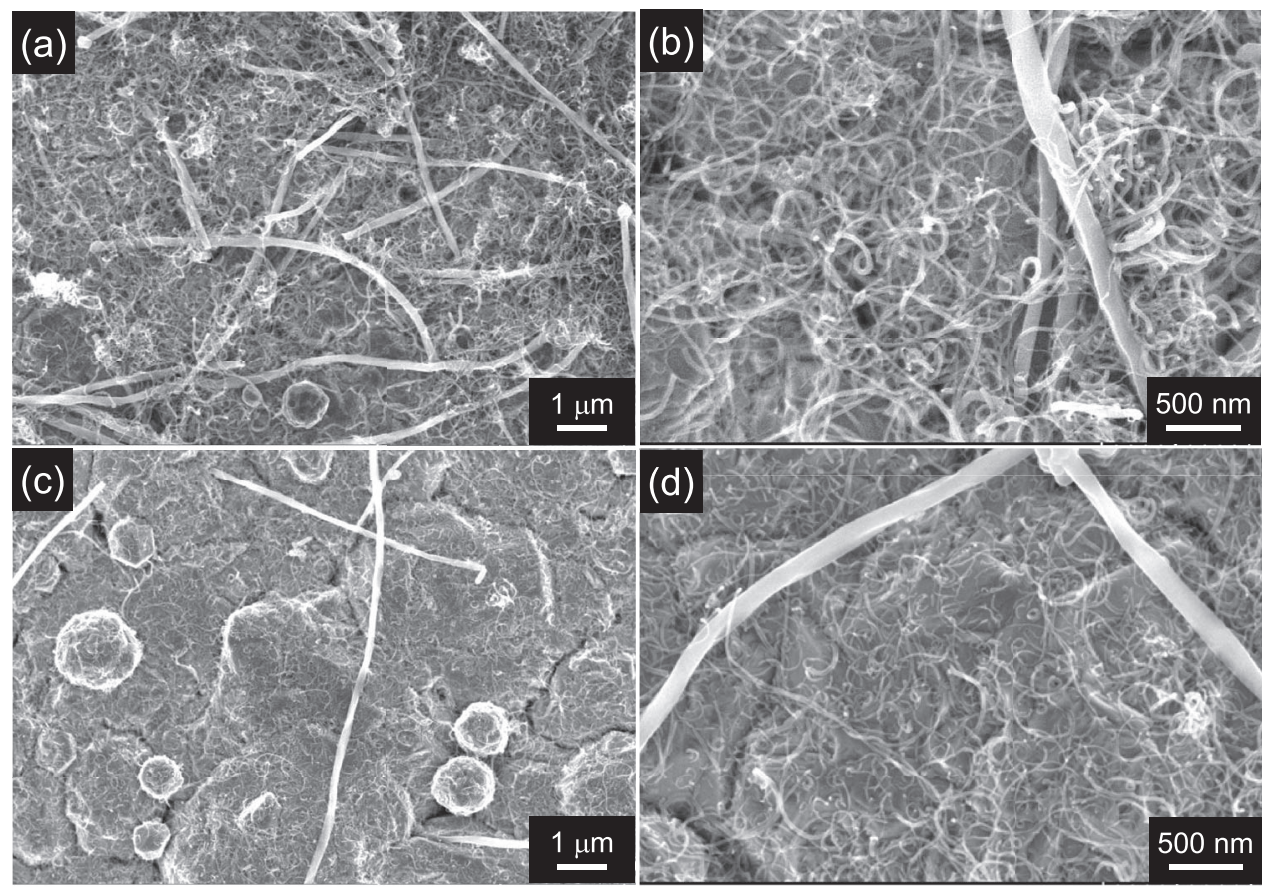

Figure 7. Surface SEM images of Cu/MWCNT composites containing different sized MWCNTs fabricated using copper deposition solutions with different SDS:HPC ratios: (a) SDS:HPC=1:1, (b) high magnification image of (a), (c) SDS:HPC=7:3, and (d) high magnification image of (c). 


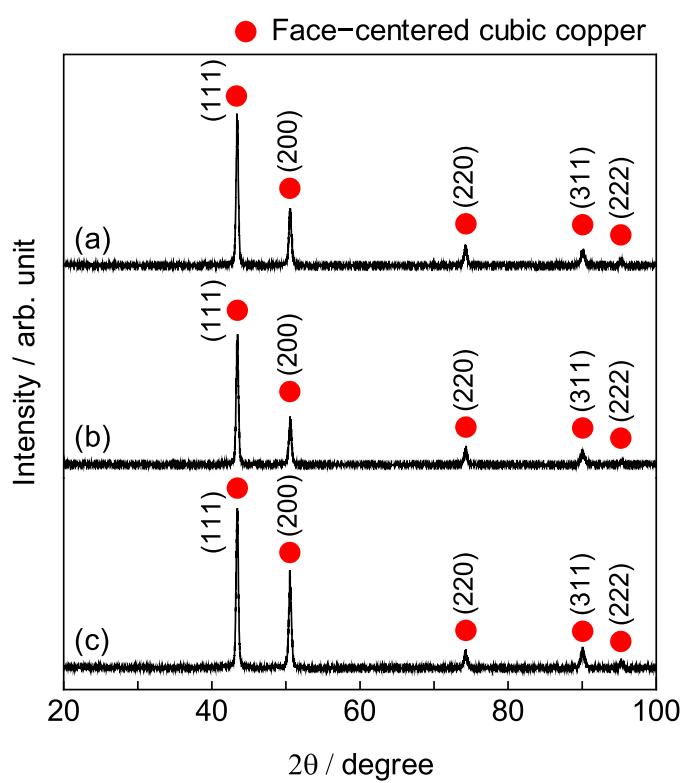

Figure 8. XRD patterns of various Cu/MWCNT composites: (a) $\mathrm{Cu} / \mathrm{MWCNT}-\mathrm{L}$ composite fabricated from the base copper deposition solution $+1 \mathrm{~g} \mathrm{~L}^{-1}$ SDS $+1 \mathrm{~g} \mathrm{~L}^{-1}$ HPC $+2 \mathrm{~g} \mathrm{~L}^{-1}$ MWCNT-L, (b) Cu/MWCNT$\mathrm{S}$ composite fabricated from the base copper deposition solution $+1 \mathrm{~g} \mathrm{~L}^{-1}$ $\mathrm{SDS}+1 \mathrm{~g} \mathrm{~L}^{-1} \mathrm{HPC}+2 \mathrm{~g} \mathrm{~L}^{-1}$ MWCNT-S, and (c) Cu/MWCNT composite containing both MWCNT-L and MWCNT-S fabricated from the base copper deposition solution $+1 \mathrm{~g} \mathrm{~L}^{-1} \mathrm{SDS}+1 \mathrm{~g} \mathrm{~L}^{-1} \mathrm{HPC}+1 \mathrm{~g} \mathrm{~L}^{-1}$ MWCNT-L $+1 \mathrm{~g} \mathrm{~L}^{-1}$ MWCNT-S.

conductive but also to non-conductive objects. Copper ions in solution are reduced to copper by accepting electrons from a reducing agent. This redox reaction occurs catalytically on the deposited copper surface. In contrast, different sized MWCNTs, that is, MWCNT-L and MWCNT-S, are dispersed homogeneously in the solution and they adsorb on the deposited copper surface. During the copper deposition process, the adsorbed MWCNTs are incorporated independently in the deposited copper, resulting in $\mathrm{Cu} / \mathrm{MWCNT}$ composites containing different sized MWCNTs homogeneously.

This unique approach has the potential to be applied to the fabrication of uniform $\mathrm{Cu} / \mathrm{CNT}$ composites containing multiple types of CNTs such as MWCNTs and singlewalled carbon nanotubes.

\section{Conclusions}

For the fabrication of $\mathrm{Cu} / \mathrm{MWCNT}$ composites containing different sized MWCNTs, an electroless copper deposition technique was applied. An anionic surfantant (SDS) and a polymeric surfactant (HPC), as well as a combination of the two, were used to disperse the large-sized and small-sized MWCNTs into the electroless copper deposition solution. Both MWCNTs were well dispersed into the solution using the combination of SDS and HPC. Cu/MWCNT composites containing different sized MWCNTs independently and homogeneously could be obtained from electroless copper deposition solutions, in which the different sized MWCNTs were dispersed homogeneously.

\section{Acknowledgment}

This work was supported by a Grant-in Aid for Scientific Research (B) (No. 26289270) from the Japan Society for the Promotion of Science (JSPS).

\section{References}

1. S. Berber, Y. K. Kwon, and D. Tomanek, Phys. Rev. Lett., 84, 4613 (2000).

2. B. Q. Wei, R. Vajtai, and P. M. Ajayan, Appl. Phys. Lett., 79, 1172 (2001).

3. M. F. Yu, O. Lourie, M. J. Dyer, K. Moloni, T. F. Kelly, and R. S. Ruoff, Science, 287, 637 (2000)

4. J. P. Lu, Phys. Rev. Lett., 79, 1297 (1997).

5. S. R. Bakshi, D. Lahiri, and A. Agarwal, Int. Mater. Rev., 55, 41 (2010).

6. K. Chu, H. Guo, C. Jia, F. Yin, X. Zhang, X. Liang, and H. Chen, Nanoscale Res. Lett., 5, 868 (2010).

7. S. Cho, K. Kikuchi, T. Miyazaki, K. Takagi, A. Kawasaki, and T. Tsukada, Scr Mater, 63, 375 (2010)

8. S. Cho, K. Kikuchi, and A. Kawasaki, Acta Mater., 60, 726 (2012).

9. E. Khaleghi, M. Torikachvili, M. A. Meyers, and E. A. Olevsky, Mater. Lett., 79, 256 (2012).

10. C. Guiderdoni, E. Pavlenko, V. Turq, A. Weibel, P. Puech, C. Estournes, A. Peigney, W. Bacsa, and C. Laurent, Carbon, 58, 185 (2013).

11. S. M. Uddin, T. Mahmud, C. Wolf, C. Glanz, I. Kolaric, C. Volkmer, H. Holler, U. Wienecke, S. Roth, and H. J. Fecht, Compos. Sci. Technol., 70, 2253 (2010).

12. C. B. Lin, Z. C. Chang, Y. H. Tung, and Y. Y. Ko, Wear, 270, 382 (2011).

13. A. K. Shukla, N. Nayan, S. V. S. N. Murty, and S. C. Sharma, Mater. Sci. Eng. A, 560, 365 (2013)

14. M. R. Akbarpour, E. Salahi, F. A. Hesari, A. Simchi, and H. S. Kim, Mater. Sci. Eng. A, 572, 83 (2013).

15. P. Jenei, E. Y. Yoon, J. Gubicza, H. S. Kim, J. L. Labar, and T. Ungar, Mater. Sci. Eng. A, 528, 4690 (2011).

16. P. Jenei, J. Gubicza, E. Y. Yoon, H. S. Kim, and J. L. Labar, Compos. Part A, 51, 71 (2013).

17. K. Rajkumar and S. Aravindan, Wear, 270, 613 (2011).

18. S. J. Yoo, S. H. Han, and W. J. Kim, Carbon, 61, 487 (2013).

19. S. Arai and M. Endo, Electrochem. Solid-State Lett., 7, C25 (2004).

20. S. Arai, T. Saito, and M. Endo, J. Electrochem. Soc., 157, D147 (2010).

21. S. Arai and A. Kato, J. Electrochem Soc., 160, D380 (2013).

22. S. Arai and T. Kanazawa, ECS J. Solid State Sci. Technology, 3, P201 (2014).

23. K. Sasaki, A. Kuroda, K. Katagiri, N. Takahashi, A. Nagai, Y. Ito, and A. Kakituji, Proceedings of the 33rd Japan Symposium on Thermophysical Properties, Osaka, Japan, Oct 3-5, 2012.

24. K. Esumi, M. Ishigami, A. Nakajima, K. Sawada, and H. Honda, Carbon, 33, 279 (1995).

25. L. Jiang and L. Gao, Carbon, 41, 2923 (2003).

26. Q. Chen, L. Dai, M. Gao, S. Huang, and A. Mau, J. Phys. Chem. B, 105, 618 (2001).

27. B. Vigolo, A. Penicaud, C. Coulon, C. Sauder, R. Pailler, C. Journet, P. Bernier, and P. Poulin, Science, 290, 1331 (2000).

28. M. J. O'Connell, S. M. Bachilo, C. B. Huffman, V. C. Moor, M. S. Strano, E. H. Haroz, K. L. Rialon, P. J. Boul, W. H. Noon, C. Kittrell, J. Ma, R. H. Hauge, R. B. Weisman, and R. E. Smalley, Science, 297, 593 (2002).

29. C. Richard, F. Balavoine, P. Schultz, T. W. Ebbesen, and C. Mioskowski, Science, 300, 775 (2003)

30. M. F. Islam, E. Rojas, D. M. Bergey, A. T. Johnson, and A. G. Yodh, Nano Lett., 3, 269 (2003).

31. V. C. Moore, M. S. Strano, E. H. Haroz, R. H. Hauge, R. E. Smalley, J. Schmidt, and Y. Talmon, Nano Lett., 3, 1379 (2003).

32. L. Jiang, L. Gao, and J. Sun, J. Colloid Interface Sci., 260, 89 (2003).

33. K. Yurekli, C. A. Mitchell, and R. Krishnamoorti, J. Am. Chem. Soc., 126, 9902 (2004).

34. T. Hertel, A. Hagen, V. Talalaev, K. Arnold, F. Hennrich, M. Kappes, S. Rosenthal, J. McBride, H. Ulbricht, and E. Flahaut, Nano Lett., 5, 511 (2005).

35. J. Steinmetz, M. Glerup, M. Paillet, P. Bernier, and M. Holzinger, Carbon, 43, 2397 (2005).

36. Y. Tan and D. E. Resasco, J. Phys. Chem. B, 109, 14454 (2005).

37. N. Grossiord, P. van der Schoot, J. Meuldijk, and C. E. Koning, Langmuir, 23, 3646 (2007).

38. Z. Sun, V. Nicolosi, D. Rickard, S. D. Bergin, D. Aherne, and J. N. Coleman, J. Phys. Chem. C, 112, 10692 (2008).

39. A. J. Blanch, C. E. Lenehan, and J. S. Quinton, J. Phys. Chem. B, 114, 9805 (2010).

40. W. H. Duan, Q. Wang, and F. Collins, Chem. Sci., 2, 1407 (2011).

41. J. N. Barisci, M. Tahhan, G. G. Wallance, S. T. Badaire Vaugien, M. Maugey, and P. Poulin, Adv. Funct. Mater, 14, 133 (2004).

42. T. Takahashi, C. R. Luculescu, K. T. Uchida Ishii, and H. Yajima, Chem. Lett., 34, $1516(2005)$

43. Y. Yan, J. Cui, P. Potschke, and B. Voit, Carbon, 48, 2603 (2010).

44. B. Suarez, B. M. Simonet, S. Cardenas, and M. Valcarcel, J. Chromagr. A, 1128, 282 (2006).

45. K. C. Park, M. Fujishige, K. Takeuchi, S. Arai, S. Morimoto, and M. Endo, J. Phys Chem. Solids, 69, 2481 (2008).

46. E. J. W. Verwey and J. Th. G. Overbeek, Theory of the Stability of Lyophobic Colloids, Elsevier, Amsterdam-New York (1948).

47. S. Shimabayashi, T. Uno, and M. Nakagaki, Colloid Surface A, 123-124, 283 (1997)

48. H. Honma and T. Kobayashi, J. Electrochem. Soc., 141, 730 (1994)

49. J. Shu, B. P. A. Grandjean, and S. Kaliaguine, Ind. Eng. Chem. Res., 36, 1632 (1997). 